\title{
PSYCHOLOGICAL DISTRESS AMONG FIRST YEAR STUDENTS IN A MEDICAL COLLEGE IN J AND K, INDIA
}

Nida Nowreen ${ }^{1}$, Farhana Ahad ${ }^{2}$

${ }_{1}^{1}$ Tutor Demonstrator, Department of Physiology, SKIMS Medical College, Bemina, Srinagar, Jammu and Kashmir, India.

${ }^{2}$ Assistant Professor, Department of Physiology, SKIMS Medical College, Bemina, Srinagar, Jammu and Kashmir, India.

ABSTRACT
BACKGROUND
Environment of medical school has rightly been recognised as stressful with the initial year being the most distressing. This study
was therefore carried out to determine the prevalence of depression, anxiety and stress among first year medical students at
SKIMS Medical College, J and K, India.

\section{MATERIALS AND METHODS}

A cross-sectional, questionnaire-based survey was carried out among the first year medical students of SKIMS Medical College using the Depression Anxiety Stress Scale-21 (DASS-21).

\section{RESULTS}

The overall response rate was $86 \%$ (86 out of 100). Depression, anxiety and stress have been reported in $65.1 \%, 77.9 \%$ and $52.3 \%$ of participants respectively. Single psychological illness was present in $20.1 \%$, while $22.0 \%$ had two and $41.8 \%$ had three coexistent psychological illnesses. No significant association was found between gender difference (Male/Female), religion (Muslim/ Non-Muslim) and habitat (Urban/ Rural) and the psychological distress in the form of depression, anxiety or stress. Significant association of present residence (Home/ Hostel) with respect to depression and anxiety was found, but the association with stress was non-significant.

\section{CONCLUSION}

The high level of psychological distress emphasises the fact that there is an urgent need for introduction of specific measures that will help in reducing depression, anxiety and stress among medical students. There is also a need for further research to be carried out on a large sample in different medical colleges of the state.

\section{KEYWORDS}

Depression, Anxiety, Stress, DASS-21.

HOW TO CITE THIS ARTICLE: Nowreen N, Ahad F. Psychological distress among first year students in a medical college in J and K, India. J. Evolution Med. Dent. Sci. 2018;7(13):1563-1566, DOI: 10.14260/jemds/2018/353

\section{BACKGROUND}

Environment of medical school has rightly been recognised as a stressful one having negative effects on the academic performance, physical and psychological well being of the students. ${ }^{[1]}$ During the initial year causes of stress are mainly related to academic and emotional factors, while in later years patient care and physical factors are more remarkable. Usually, the excessive working hours, competitive academic environment, lack of recreational activities, lack of peer support, staying away from home and financial problems are the common reasons for the development of anxiety and stress in medical schools.[2]

The assessment of stress during various phases of medical education has revealed that first and second years are the most stressful. Although, a majority of the students seemed to cope well with the stress, a subgroup with dysfunctional and inadequate strategies was identified to be at risk for negative development. [3]

'Financial or Other Competing Interest': None.

Submission 15-02-2018, Peer Review 11-03-2018,

Acceptance 17-03-2018, Published 26-03-2018.

Corresponding Author:

Dr. Nida Nowreen,

W/o, Junaid Akhtar,

R/o. H. No. 4, Sector E-2, Jeelanabad Colony, Peerbagh,

Srinagar-190014, Jammu and Kashmir, India.

E-mail: nowreen.n3@gmail.com

DOI: $10.14260 /$ jemds $/ 2018 / 353$

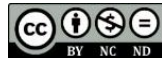

Studies among medical students have found out that stress is associated with anxiety and depression.[4,5] Moreover, stress has also been linked to suicide among medical students.[6]

Inability to identify the psychological problems among medical students may lead to increased morbidity with undesired effects throughout their careers and lives. ${ }^{[7]}$ On the other hand, knowledge about contributing factors of emotional status of recently admitted MBBS student can help in taking necessary actions to prevent or treat any psychiatric morbidity like depression, anxiety and stress. Thus, helping in production of competent physicians who can face challenges of this new profession.[8]

Psychological morbidity in course of medical education has attracted increasing attention in recent years. But such studies on medical students, especially freshmen who are exposed to the transitional nature of college life are lacking from our state. This study was, therefore, carried out to determine the prevalence of depression, anxiety and stress among first year medical students at SKIMS Medical College, Srinagar (V and K, India).

\section{MATERIALS AND METHODS}

The present cross-sectional study was conducted on first year students of SKIMS Medical College, Srinagar (J and K) from January 2017 to March 2017. Participation was voluntary, and confidentiality was assured. At the time when the study was being conducted, the students were having no major exams. 
Two self-administered questionnaires were used to collect data. The first was a questionnaire for identifying socio-demographic characters and the second was the short version of the Standardised Depression Anxiety Stress Scale (DASS) - 21 item questionnaire, it is a set of three self-report scales designed to identify the presence and measure severity of the negative emotional states of depression, anxiety and stress. Each subscale has seven items. Respondents are asked to use 4-point severity/ frequency scales to rate the extent to which they had experienced each state over the past one week. Each item is scored from 0 (Did not apply to me at all over the last week) to 3 (applied to me very much or most of the time over the past one week). Because the DASS- 21 is a short form version of the DASS (the Long Form has 42 items), the final score of each item groups (Depression, Anxiety and Stress) must be multiplied by two $(\times 2)$ to obtain the final score.[9]

For data analysis, IBM-SPSS (Statistical Package of Social Sciences) version 11 was used. Chi-square test and Fisher's exact test were used as a test of significance. $\mathrm{P} \leq 0.05$ was considered statistically significant.

\section{RESULTS}

Out of the 100 students that participated in the study, 86 returned the filled questionnaire. Their mean age was $17.96 \pm$ 0.78 years with a range of $17-20$ years. Half of participants $(50 \%)$ were males and half were females $(50 \%)$.

\begin{tabular}{|c|c|c|}
\hline Studied Variable & No. of Students & $\%$ \\
\hline \multicolumn{3}{|l|}{ Gender } \\
\hline Male & 43 & 50 \\
\hline Female & 43 & 50 \\
\hline Total & 86 & 100 \\
\hline \multicolumn{3}{|l|}{ Habitat } \\
\hline Rural & 41 & 47.67 \\
\hline Urban & 45 & 52.23 \\
\hline Total & 86 & 100 \\
\hline \multicolumn{3}{|l|}{ Religion } \\
\hline Muslims & 68 & 79.06 \\
\hline Non-Muslim & 18 & 20.93 \\
\hline Total & 86 & 100 \\
\hline \multicolumn{3}{|l|}{ Present Address } \\
\hline Home & 29 & 33.72 \\
\hline Hostel & 57 & 66.27 \\
\hline Total & 86 & 100 \\
\hline
\end{tabular}

Depression, anxiety and stress were reported in $65.1 \%$, $77.9 \%$ and $52.3 \%$ of participants respectively. Symptoms of mild severity were mainly prevalent in anxiety and stress subscales, but for depression symptoms of moderate severity were predominant (Table 2).

\begin{tabular}{|c|c|c|c|}
\hline Severity & Depression & Anxiety & Stress \\
\hline & $\begin{array}{c}\text { No. of } \\
\text { Students (\%) }\end{array}$ & $\begin{array}{c}\text { No. of } \\
\text { Students (\%) }\end{array}$ & $\begin{array}{c}\text { No. of } \\
\text { Students (\%) }\end{array}$ \\
\hline Mild & $14(16.28)$ & $23(26.74)$ & $16(18.60)$ \\
\hline Moderate & $21(24.42)$ & $13(15.12)$ & $12(13.95)$ \\
\hline Severe & $10(11.63)$ & $10(11.63)$ & $13(15.12)$ \\
\hline $\begin{array}{c}\text { Extremely } \\
\text { Severe }\end{array}$ & $11(12.79)$ & $21(24.42)$ & $4(4.65)$ \\
\hline Total & $\mathbf{5 6 ( 6 5 . 1 2 )}$ & $\mathbf{6 7 ( 7 7 . 9 1 )}$ & $\mathbf{4 5 ( 5 2 . 3 2 )}$ \\
\hline
\end{tabular}

Table 2. Depression, Anxiety and Stress among Studied Group of First Year Medical Students

Only $15.1 \%$ of participants were found to be normal. $20.9 \%$ suffered from single psychological illness, while two and three coexistent psychological illnesses were found in $22.0 \%$ and $41.8 \%$ of participants, respectively (Fig. 1).

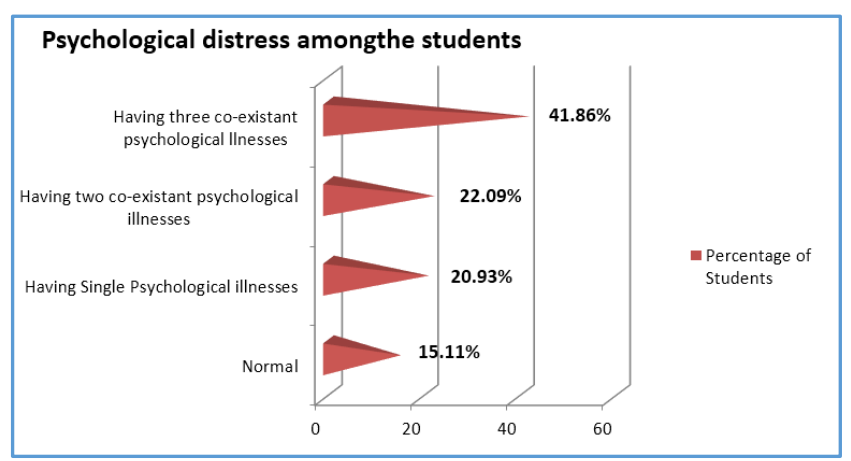

Figure 1

Table 3 shows the association of socio-demographic variables like gender (Male/ Female), habitat (Rural/ Urban), present residence (Home/ Hostel) and religion (Muslim/NonMuslim) with the psychological distress in the form of depression, anxiety and stress.

\begin{tabular}{|c|c|c|c|c|c|c|c|c|c|}
\hline \multirow{2}{*}{ Variables } & \multicolumn{3}{|c|}{ Depression } & \multicolumn{3}{|c|}{ Anxiety } & \multicolumn{3}{|c|}{ Stress } \\
\hline & Frequency (\%) & $\chi^{2}$ Value & $\mathbf{P}$ & Frequency (\%) & $\chi^{2}$ Value & $\mathbf{P}$ & Frequency (\%) & $\chi^{2}$ Value & $\mathbf{P}$ \\
\hline \multicolumn{10}{|l|}{ Gender } \\
\hline Male & $30(69.76 \%)$ & 2.066 & 0.724 & $38(88.37 \%)$ & 2.242 & 0.69 & $26(60.40 \%)$ & 5.221 & 0.265 \\
\hline Female & $26(60.45 \%)$ & & & $36(74.41 \%)$ & & & $19(44.18 \%)$ & & \\
\hline \multicolumn{10}{|l|}{ Habitat } \\
\hline Rural & $28(68.29 \%)$ & 1.27 & 0.867 & $36(87.80 \%)$ & 5.858 & 0.21 & $24(58.53 \%)$ & 1.422 & 0.84 \\
\hline Urban & $28(62.22 \%)$ & & & $31(75.60 \%)$ & & & $21(51.21 \%)$ & & \\
\hline \multicolumn{10}{|c|}{ Present Residence } \\
\hline Home & $16(55.17 \%)$ & 11.9 & $0.018^{*}$ & $19(65.51 \%)$ & 9.514 & $0.05^{*}$ & $13(44.82 \%)$ & 8.39 & 0.78 \\
\hline Hostel & $40(70.17 \%)$ & & & $48(84.21 \%)$ & & & $32(56.14 \%)$ & & \\
\hline \multicolumn{10}{|l|}{ Religion } \\
\hline Muslim & $45(66.16 \%)$ & 2.522 & 0.641 & $52(76.47 \%)$ & 3.581 & 0.47 & $35(51.47 \%)$ & 5.676 & 0.225 \\
\hline $\begin{array}{l}\text { Non- } \\
\text { Muslim }\end{array}$ & $11(61.11 \%)$ & & & $15(83.33 \%)$ & & & $10(55.55 \%)$ & & \\
\hline \multicolumn{10}{|c|}{ Table 3. Association of Socio-Demographic Variables with Depression, Anxiety and Stress } \\
\hline
\end{tabular}

$* \mathrm{p} \leq 0.05=$ Significant. 
Prevalence of psychological morbidity was found to be higher in males as compared to females. Percentage of male and female suffering from depression was $69.76 \%$ and $60.45 \%$; anxiety was $88.37 \%$ and $74.41 \%$ and stress was $60.40 \%$ and $44.18 \%$ respectively. No significant association was found between gender difference, religion and habitat, and the psychological distress in the form of depression, anxiety or stress. Significant association of present residence with respect to depression and anxiety was found, but the association with stress was non-significant.

\section{DISCUSSION}

Medical education is very stressful and demanding. Overwhelming load of information leaves little opportunity for the students to relax and recreate.[10] Studies have proved that compared to the general population, medical students are the most distressed students.[11] Medical education has been perceived as stressful globally and different studies have reported high prevalence of stress among medical students.[1,12,13] Medical students face stressors specific to medical education in addition to normal stressors of everyday life, which could explain this high prevalence of psychological illnesses among them.[14] Studies have also attributed high level of Anxiety and Depression in first year students to the new study environment.[15]

Our study has revealed a high level of psychological distress among first year medical students. Anxiety was found to be the most prevalent form of distress with a prevalence of $77.9 \%$ followed by depression (65.1\%) and stress (52.3\%). Similar values of stress and anxiety have been reported by other studies conducted in the Indian subcontinent, but the prevalence of depression in them was lower.[16,17]

High prevalence of depression has also been reported in general Kashmiri population.[18] This may be due to the fact that people living in conflict are at a higher risk of developing psychological distress.[19] Double and triple co-existent illnesses were reported in $22.0 \%$ and $41.8 \%$ of participants, respectively. This percentage, although high, is lower than in other studies who reported prevalence of two co-existent illnesses to be $60 \%-70 \%$.[20,21] But as these studies used a different scale for assessment of psychological distress, comparison of their results with our study has to be done cautiously.

No significant association was found with gender difference (Male/Female) and psychological distress, though the prevalence of depression, anxiety and stress were found to be higher in males as compared to females. Our study is in contrast with most studies, which report higher levels of distress in females.[22,23] Our study is in accordance with a study conducted in Bangladesh,[24] which reported higher levels stress in males. No significant association was found between any of the DASS subscale (Depression, Anxiety and Stress) and variables like habitat and religion.

It was observed that students living in the hostel had higher prevalence of depression and anxiety compared to those living at home and the association was significant. No significant association was found between stress subscale and present residence (living in home or hostel). Similarly in a study, Pakistani female medical students living in college hostel were found to be significantly more depressed and had the tendency to report anxiety more than those living at home.[25]

Our study was not free from limitations. The sample size was small, and data was collected from a single medical college in the state. There is need for further research to be carried out on a large sample in different medical colleges of the state.

\section{CONCLUSION}

The high level of psychological distress emphasises the fact that there is an urgent need for introduction of specific measures that will help in reducing depression, anxiety and stress among medical students. Certain preventive measures that can help in reducing distress are promotion of a healthy lifestyle, introduction of stress reduction programs and recreational activities in the curriculum and by encouraging positive coping styles. It is high time to bring certain changes in the extremely stressful examination system. Counselling services should be made available to students. Assessment of mental health of medical students should be done at entry level with regular follow-up of those having mental illnesses. Early detection and intervention will not only reduce the level of distress among students, but will also have a positive effect on their personal, social and professional development.

\section{REFERENCES}

[1] Firth-Cozens J. Medical student stress. Med Educ 2001;35(1):6-7.

[2] Wolf TM. Coping and health: enhancing well-being during medical school. Med Educ 1994;28(1):8-17.

[3] Niemi PM, Vainiomaki PT. Medical students' academic distress, coping and achievement strategies during the preclinical years. Teaching and Learning in Medicine 1999;11(3):125-34.

[4] Shapiro SL, Shapiro DE, Schwartz GE. Stress management in medical education: a review of the literature. Acad Med 2000;75(7):748-59.

[5] Rosal MC, Ockene IS, Ockene JK, et al. A longitudinal study of students' depression at one medical school. Acad Med 1997;72(6):542-6.

[6] Hays LR, Cheever T, Patel P. Medical student suicide. 1989-1994. Am J Psychiatry 1996;153(4):553-5.

[7] Tyssen R, Vaglum P, Gronvold NT, et al. Suicidal ideation among medical and young physicians: a nationwide and prospective study of prevalence and predictors. J Affect Disord 2001;64(1):69-79.

[8] Saslow G. Psychiatric problems of medical students. J Med Edu 1956;31(1):27-33.

[9] Lovibond SH, Lovibond PF. Manual for the Depression Anxiety Stress Scales. 2nd edn. Sydney: Psychology Foundation of Australia 1995.

[10] Hoe DC, Wah CK, Rian CA, et al. Stress manifestations of medical students and its relation with gender and life style changes. Int Med J Stud Res 2012;2:37-45.

[11] Lloyd C, Gartrell NK. Psychiatric symptoms in medical students. Comprehensive Psychiatry 1984;25(6):55265.

[12] Dahlin M, Joneborg N, Runeson B. Stress and depression among medical students: a cross-sectional study. Med Educ 2005;39(6):594-604. 
[13] Bayram N, Bilgel N. The prevalence and sociodemographic correlations of depression, anxiety and stress among a group of university students. Soc Psychiatry \& Psychiatry Epidemiol 2008;43(8):66772.

[14] Jadoon NA, Yaqoob R, Raza A, et al. Anxiety and depression among medical students: a cross-sectional study. J Pak Med Assoc 2010;60(8):699-702.

[15] Shah M, Hasan S, Malik S, et al. Perceived stress, sources and severity of stress among medical undergraduates in a Pakistani Medical School. BMC Med Educ 2010;10:2.

[16] Vaidya PM, Mulgaonkar KP. Prevalence of depression, anxiety \& stress in undergraduate medical students \& its correlation with their academic performance. IJOT 2007;39(1):7-10.

[17] Abdallah AR, Gabr HM. Depression, anxiety and stress among first year medical students in an Egyptian public university. International Research Journal of Medicine and Medical Sciences 2014;2(1):11-19.

[18] Housen T, Lenglet A, Ariti C, et al. Prevalence of anxiety, depression and post-traumatic stress disorder in the Kashmir Valley. BMJ Global Health 2017;2(4):e000419.
[19] Scholte WF, Olff M, Ventevogel P, et al. Mental health symptoms following war and repression in eastern Afghanistan. JAMA 2004;292(5):585-93.

[20] Inam SNB, Saqib A, Alam E. Prevalence of anxiety and depression among medical students of private university. J Pak Med Assoc 2003;53(2):44-7.

[21] Khan MS, Mahmood S, Badshah A, et al. Prevalence of depression, anxiety and their associated factors among medical students in Karachi, Pakistan. J Pak Med Assoc 2006;56(12):583-6.

[22] Supe AN. A study of stress in medical students at Seth G.S. Medical College. Journal of Postgraduate Medicine 1998;44(1):1-6.

[23] Abdulghani HM, Alkanhal AA, Mahmoud ES, et al. Stress and its effects on medical students: a crosssectional study at a college of medicine of Saudi Arabia. J Health Popul Nutr 2011;29(5):516-22.

[24] Sultana N. Stress and depression among undergraduate medical students of Bangladesh. Bangladesh Journal of Medical Education 2011;2(1):69.

[25] Rab F, Mamdou R, Nasir S. Rates of depression and anxiety among female medical students in Pakistan. East Mediterr Health J 2008;14(1):126-33. 